Article

\title{
Preparation of the Water-Soluble Pyrene-Containing Fluorescent Polymer by One-Pot Method
}

\author{
Xiaomeng Li, Miaomiao Wang, Haijian Tan, Qingmin Yang, Aiqing Wang, Libin Bai, \\ Hongchi Zhao * and Yonggang $\mathrm{Wu}$ * \\ Received: 22 September 2015; Accepted: 4 December 2015; Published: 9 December 2015 \\ Academic Editor: Shin-ichi Yusa \\ College of Chemistry and Environmental Science, Hebei University, Baoding 071002, China; \\ mengzhu506@163.com (X.L.); wmmzxcv@163.com (M.W.); 15932279203@163.com (H.T.); \\ yangtian_qingmin@126.com (Q.Y.); waqing@hbu.edu.cn (A.W.); zhonggou556@hbu.edu.cn (L.B.) \\ * Correspondence: zhc@hbu.edu.cn (H.Z.); wuyonggang@hbu.edu.cn (Y.W.); \\ Tel./Fax: +86-312-5079317 (H.Z. \& Y.W.)
}

\begin{abstract}
A new water-soluble pyrene-containing fluorescent polymer, 1-\{3'-S-[poly(acryloyl ethylene diamine hydrochloride)-2'-methyl propionic acid]\}propionyloxy hexyloxy pyrene (P3) with defined structure, was designed and synthesized using the click reaction between thiol and a carbon-carbon double bond. The intermediate products P1 (S-1-dodecyl- $S^{\prime}$-[poly(N-Boc-acryloyl ethylene diamine)-2'-methyl propionic acid]trithiocarbonate) and AHP (1-(acryloyloxy hexyloxy)pyrene) were prepared via reversible addition fragmentation chain transfer (RAFT) polymerization and Williamson synthesis, respectively. Conjugating AHP with P1, P2 (1-\{3'-S-[poly(N-butoxycarbonyl-acryloyl ethylene diamine)-2"-methyl propionic acid]\} propionyloxy hexyloxy pyrene) was synthesized, adopting both the reduction reaction of a trithioester bond of $\mathbf{P 1}$ to thiol and the click reaction between thiol and the carbon-carbon double bond of AHP simultaneously. P3 was obtained by the deprotection of the resulting Boc-protected polymer (P2) with aqueous $\mathrm{HCl}$. The experiment results showed that P2 exhibited a bright blue-violet emission band at approximately $387-429 \mathrm{~nm}$. After deprotection, P3 displayed good solubility in water and not only exhibited a blue-violet fluorescence emission band at approximately $387-429 \mathrm{~nm}$ in aqueous solution but also had the similar photoluminescent spectra to those of AHP and $\mathbf{P} \mathbf{2}$ in dichloromethane. The fluorescence quantum yields of $\mathbf{P} \mathbf{2}$ in dilute tetrahydrofuran and $\mathbf{P 3}$ in a dilute aqueous solution were 0.44 and 0.39 , respectively. This experiment provided a novel insight into the study of water-soluble fluorescent polymers.
\end{abstract}

Keywords: pyrene; water-soluble fluorescent polymer; click-chemistry; thiol-ene reaction; reversible addition-fragmentation chain transfer (RAFT)

\section{Introduction}

Water-soluble fluorescent polymers have drawn much attention in recent years given their successful utility in distinguishing different proteins [1] and isozymes [2], as an effective and sensitive probe for further bio-applications differentiating tumorous and malignant cells [3,4], ranging from cytotoxicity studies to pharmacodiagnosis. Water is usually regarded as an ideal solvent in terms of its environmental impact and low cost. Water solubility is a prerequisite of those fluorescent polymers for applications in biological environments [5,6], since as long as the fluorescent polymers enjoy water solubility they can be uniformly dispersed in the aqueous medium of the system under characterization. The water-soluble fluorescent polymers in the field of applied biotechnology research exhibited unique advantages. To tackle this issue, several designed strategies to prepare water-soluble fluorescent polymers, mainly including copolymerization and chemical modification, have been well established and applied to the development of various excellent fluorescent polymers. Co-polymerization is 
a family of methods that fluorochrome copolymerizes directly with a water-soluble monomer. It has been demonstrated to be a simple, effective strategy to obtain a water-soluble copolymer, but it generally enjoys several limitations due to low molecular weight, poor water-solubility and low fluorescence intensity. Chemical modification method that was also the designed strategy in this contribution, which was chemically bonded to the fluorescent dye on the polymer chain or born hydrophilic groups to fluorescent polymers. Water-soluble poly(acrylic acid) has been covalently labeled with a fluorescent hydrophobic chromophore, naphthalene $(\mathrm{Np})$, randomly attached onto the polymer backbone with an amount of $3 \mathrm{~mol} \%[7,8]$. Curtis W. Frank and co-workers $[9,10]$ reported that pyrene end-labeled poly(ethylene glycol) (PEG) was synthesized by direct esterification between PEG and l-pyrenebutyric acid (PBA). As an important and widespread tool in biomedical research and disease diagnosis $[4,11]$, water-soluble fluorescent polymers with suitable molecular weight may be used for fluorescent detection of protein and image in the cells [12].

In order to obtain the polymer with controlled and narrow distribution of molecular weight, living radical polymerization is a conventional polymerization method. Reversible addition-fragmentation chain transfer (RAFT) polymerization is one of the most popular living radical polymerization methods for the production of well-defined polymers. After polymerization, the RAFT agent end-groups can easily be converted into thiol, opening manifold opportunities for thiol modification reactions [13]. The functional groups are effectively introduced into the polymer terminal groups by these reactions, such as thiol-ene [13], thiol-epoxy reaction [14], and so on. Such reaction of thiol and epoxy, alkenes, and alkynes is one kind of click-chemistry reactions.

The past decade has seen the emergence of "click chemistry"; the term "click chemistry" defines a series of chemical reactions respecting several criteria announced in 2001 by Sharpless and co-workers [15]. Click chemistry is addressing a set of powerful, highly-reliable, and selective reactions for the rapid synthesis of useful new compounds and combinatorial libraries [16]. Click chemistry possesses many significant advantages, such as a certain modularity [17], excellent selectivity, high purity, high efficiency, a wide scope of applications, only inoffensive byproducts, stereospecific, mild reaction conditions, and simple product isolation, etc. [15,18-20]. Since S-H bonds are relatively weak, thiol groups are subject to rapid oxidation during purification and storage and, thereby, result in the low conversion in the following click reaction. To circumvent this limitation, the synthesis of thiol groups and click reaction were simultaneously performed in one system (one-pot method). Highly efficient reactions of thiols with the reactive carbon-carbon double bond [20] (thiol-ene click-chemistry reaction) is one of the most mature click-chemistry reactions, in which thiol can rapidly react with the terminal $\mathrm{C}=\mathrm{C}$ double bond to form a $\mathrm{C}-\mathrm{S}$ bond under mild conditions, which has been applied in diverse preparation areas, such as functional polymer nanoparticles [21] and beads [22], amphipathic well-defined polymers [23], desired dendritic macromolecules [24], nanocapsules [25], substrate surface modification [20], polymer functionalization [26], and so forth.

The pyrene moiety is one of the most useful fluorophores due to its striking efficiency among excimer formation and subsequent changes in its emission properties [27]. Pyrene can emit blue fluorescence with a high fluorescence quantum yield $(0.65$, acetonitrile) and a long fluorescence lifetime (440 ns, a cyclohexane solution, $290 \mathrm{~ns}$, ethanol) [28] responsible to the unique polycyclic aromatic hydrocarbon-conjugated structure. Therefore, pyrene is an important signaling unit, which is widely used for various analytes [29-31]. However, pyrene, or other conventional fluorescent molecules with alternating single and double bond conjugated structures, are faced with the thorny aggregation problem leading to emission spectrum red-shift and fluorescence quenching. There were several projects to avoid this phenomenon by introducing large steric groups at reactive sites of pyrene to avoid the accumulation of the conjugated plane [32,33]. However, most of the works were studies of the responses and characteristics when pyrene-containing polymers dissolved in organic solvent. For example, the fluorescence quantum yield and infrared absorption spectrum of pyrene derivatives in Robert M. Edkins' experiment showed the dependency of the solvent [34]. This article will discuss 
how the pyrenyl functional end group is introduced into a water-soluble polymer, which is applied to the light emitting properties of pyrene in aqueous solution.

In this study, S-1-dodecyl-S'-[poly(N-Boc-acryloyl ethylene diamine)-2'-methyl propionic acid]trithiocarbonate (P1) was prepared via RAFT polymerization using N-Boc-acryloyl ethylene diamine as a monomer. Boc-protected fluorescent polymer (P2) with regular structure was synthesized using the click reaction of thiol (the reduction reaction production of trithioester bond of P1) and the carbon-carbon double bond of AHP. Water-soluble pyrene-containing fluorescent polymer (P3) was obtained by the deprotection of the resulting Boc-protected polymer (P2). P3 was characterized and measured by Fourier transform infrared spectrophotometry, nuclear magnetic resonance spectrometry, UV-Visible (UV-VIS) spectrophotometry, and fluorescence spectrophotometry, respectively, and the fluorescence quantum yield of $\mathbf{P 3}$ in aqueous solution was obtained. The fluorescent polymer $\mathbf{P} \mathbf{3}$ had good water solubility and also showed good optical performance.

\section{Experimental Section}

\subsection{Reagents}

1-Hydroxypyrene (HP, 98.5\%) was purchased from Jiangsu Rich-chem Co., Ltd., Taizhou, China. 1,6-Dibromohexane (98\%) was purchased from J\&K scientific Co., Ltd. (Beijing, China). 9,10-diphenylanthracene (DPA, $>95.0 \%$ ) was purchased from TCI (Shanghai, China) Development Co., Ltd. (Shanghai, China) Di(tert-butyl) dicarbonate $\left(\mathrm{Boc}_{2} \mathrm{O}, 97+\%\right)$ was purchased from Apollo Scientific Limited (Beijing, China). Anhydrous sodium sulfate, ethylenediamine, and triethylamine (TEA) were all analytically-pure grades and were supplied by Tianjin Kemiou Chemical Reagent Co., Ltd. (Tianjin, China). Sodium borohydride $\left(\mathrm{NaBH}_{4}\right)$, acryloyl chloride, acrylic acid, sodium hydroxide, tetrahydrofuran (THF), petroleum ether, dichloromethane (DCM), and anhydrous methanol were all analytically-pure grades and were supplied by Sinopharm Chemical Reagent Beijing Co., Ltd. (Beijing, China). THF and DCM were distilled prior to use. Deionized water was used in the experiment.

\subsection{Instruments and Measurements}

Fourier transform infrared (FTIR) spectra were recorded on a Varian 640-IR FTIR spectrophotometer (Varian, Salt Lake City, UT, USA) using KBr pellets. Nuclear magnetic resonance spectroscopy (NMR) was performed on a Bruker AVANCE III $600 \mathrm{MHz}$ digital NMR spectrometer (Bruker, Zurich, Switzerland) using $\mathrm{CDCl}_{3}$ and $\mathrm{D}_{2} \mathrm{O}$ as solvent at room temperature. Chemical shifts were measured using tetramethylsilane (TMS) as an internal standard. The number average molecular weight $\left(M_{\mathrm{n}}\right)$, weight average molecular weight $\left(M_{\mathrm{w}}\right)$, and polydispersity index (PDI, $\left.M_{\mathrm{w}} / M_{\mathrm{n}}\right)$ of polymers were determined by a Waters 515 gel permeation chromatograph (GPC) (Waters, Milford, MA, USA). Two chromatographic columns (Agilent Technologies, PLgel $5 \mu \mathrm{m} 500 \AA$, PLgel $5 \mu \mathrm{m}$ Mixed-C) were used in series. THF was used as eluent at a flow rate of $1.0 \mathrm{~mL} / \mathrm{min}$ at $30^{\circ} \mathrm{C}$. Universal calibration was done using seven standard polystyrene samples $(1600,3790,6000,11,500,44,700,105,800$, and 903,000). High-resolution atmospheric pressure-chemical ionization Fourier-transform ion cyclotron resonance mass-spectroscopy (HR-APCI-FT-ICR-MS) was performed on a Bruker Daltonik apex-Ultra 7.0 T Fourier-transform ion cyclotron resonance mass spectrometer (Bruker, Bremen, Germany) equipped with an atmospheric pressure chemical ionization source operating in the nebulizer-assisted electrospray mode. The sample was dissolved in methanol (high-performance liquid chromatography grade) solvent. The sample molecule was ionized with $\mathrm{H}^{+}$ions. UV-VIS spectra were recorded on a UV-2550 spectrophotometer (Shimadzu, Kyoto, Japan). Photoluminescent (PL) spectra were recorded on a RF-5301PC fluorescence spectrophotometer (Shimadzu, Kyoto, Japan).

\subsection{Synthesis of N-Butoxycarbonyl-Ethylene Diamine (N-Boc-EDA)}

$\mathrm{N}$-Boc-EDA was synthesized according to published literature [35]. Ethylenediamine (30 $\mathrm{mL}$, $448 \mathrm{mmol})$ and THF $(150 \mathrm{~mL})$ were placed into a $500 \mathrm{~mL}$ round-bottom flask with moderate stirring 
at -5 to $0{ }^{\circ} \mathrm{C}$. Then, the THF $(100 \mathrm{~mL})$ solution of $\mathrm{Boc}_{2} \mathrm{O}(20 \mathrm{~mL}, 87.06 \mathrm{mmol})$ was added dropwise into the cold mixture. After the addition, the reaction was continued for $24 \mathrm{~h}$ at room temperature, and a white suspension was obtained. The white suspension was filtered and the filtrate was rotary evaporated to give a pale yellow oily liquid. Then the liquid was washed extensively with saturated $\mathrm{NaCl}$ aqueous solution and filtered. The filtrate was extracted with ethyl acetate three times, and the combined organic layer was dried over anhydrous $\mathrm{Na}_{2} \mathrm{SO}_{4}$ overnight and filtered. Solvents were removed by rotary evaporation to give $\mathrm{N}$-Boc-EDA as a pale yellow oily liquid $0.11 \mathrm{~g}$ (yield $73 \%$ ). ${ }^{1} \mathrm{H}$ NMR $\left(600 \mathrm{MHz}, \mathrm{D}_{2} \mathrm{O}\right) \delta(\mathrm{ppm}): 3.02(\mathrm{t}, J=6.0 \mathrm{~Hz}, 2 \mathrm{H}), 2.58(\mathrm{t}, J=6.0 \mathrm{~Hz}, 2 \mathrm{H}), 1.34(\mathrm{~s}, 9 \mathrm{H})$.

\subsection{Synthesis of N-Butoxycarbonyl-Acryloyl Ethylene Diamine (N-Boc-AEDA)S}

$\mathrm{N}$-Boc-AEDA was synthesized according to published literature [35]. N-Boc-EDA (0.72 g, $4.5 \mathrm{mmol})$, triethylamine (TEA, $0.55 \mathrm{~g}, 5.4 \mathrm{mmol})$, and DCM $(20 \mathrm{~mL})$ were added to a $100 \mathrm{~mL}$ round-bottom flask and stirred at $0^{\circ} \mathrm{C}$. Then, the solution of acryloyl chloride $(0.41 \mathrm{~g}, 4.5 \mathrm{mmol})$ in DCM $(15 \mathrm{~mL})$ was added dropwise, and then the reaction was continued for $15 \mathrm{~h}$ at room temperature. After the reaction finished, saturated $\mathrm{NaHCO}_{3}(40 \mathrm{~mL})$ aqueous solution was added to the mixture. The organic layer was separated and dried over anhydrous $\mathrm{Na}_{2} \mathrm{SO}_{4}$ and filtered. Solvents were removed by rotary evaporation to give a pale yellow solid. The pale yellow solid was chromatographed on a column of silica gel with ethyl acetate: $n$-hexane $(7: 3, V: V)$ as eluent, and white solid $N$-Boc-AEDA $0.826 \mathrm{~g}$ (yield 86\%) was obtained. ${ }^{1} \mathrm{H}$ NMR $\left(600 \mathrm{MHz}, \mathrm{CDCl}_{3}\right) \delta(\mathrm{ppm}): 6.26(\mathrm{~d}, J=16.8 \mathrm{~Hz}, 1 \mathrm{H}), 6.12$ $(\mathrm{dd}, J=16.8 \mathrm{~Hz}, 10.8 \mathrm{~Hz}, 1 \mathrm{H}), 5.63(\mathrm{~d}, J=10.2 \mathrm{~Hz}, 1 \mathrm{H}), 3.45-3.43(\mathrm{~m}, 2 \mathrm{H}), 3.33-3.30(\mathrm{~m}, 2 \mathrm{H}), 1.43(\mathrm{~s}, 9 \mathrm{H})$.

\subsection{Synthesis of S-1-Dodecyl-S'-( $\alpha, \alpha^{\prime}$-Dimethyl- $\alpha^{\prime \prime}$-Acetic Acid)trithiocarbonate and}

\section{S-1-Dodecyl-S'-[poly(N-Boc-Acryloyl Ethylene Diamine)-2'-Methyl Propionic Acid]trithiocarbonate (P1)}

$S$-1-dodecyl-S'-( $\alpha, \alpha^{\prime}$-dimethyl- $\alpha^{\prime \prime}$-acetic acid)trithocarbonate (RAFT agent) was synthesized according to published literature [36]. P1 was synthesized according to procedures in the literature [37]. The reaction mechanism of P1 was shown in Scheme 1. N-Boc-AEDA (6.000 g, $28.08 \mathrm{mmol})$ and solvent THF (30 mL) were mixed in a $100 \mathrm{~mL}$ eggplant-shaped flask with magnetic stirring and dissolved completely. RAFT agent $(0.600 \mathrm{~g}, 1.64 \mathrm{mmol})$ and AIBN $(0.048 \mathrm{~g}, 0.29 \mathrm{mmol})$ were added. The mixture was refluxed for $5 \mathrm{~h}$ under a nitrogen atmosphere. THF was removed by rotary evaporation to give a pale yellow solid. It was washed with water several times, dried in a vacuum oven to afford P1 as a yellow solid (6.402 $\mathrm{g}$, yield $97 \%)$.

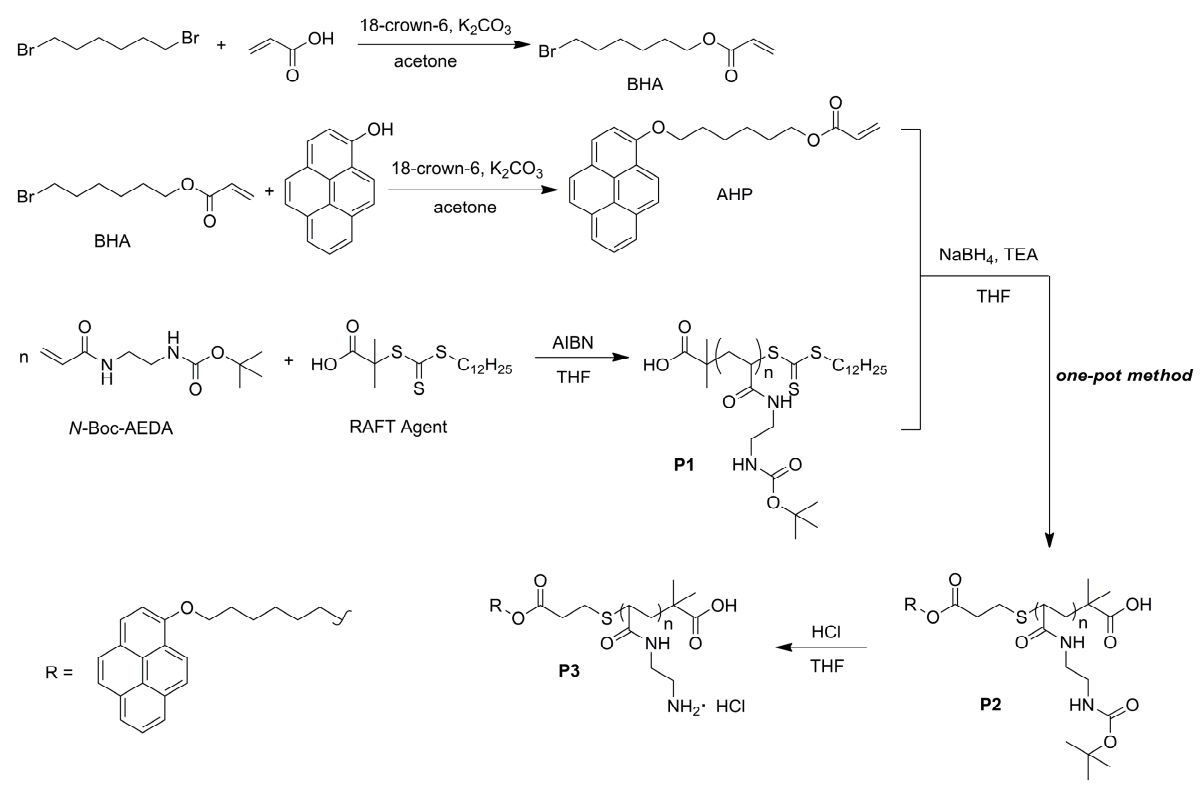

Scheme 1. The reaction routes of BHA, AHP, P1-P3. 


\subsection{Synthesis of 6-Bromohexyl Acrylate (BHA)}

The reaction mechanism of BHA was shown in Scheme 1. BHA was synthesized according to procedures in the literature [37].

\subsection{Synthesis of 1-(Acryloyloxy Hexyloxy)pyrene (AHP)}

The reaction mechanism of AHP was shown in Scheme 1. HP (0.65 g, $3 \mathrm{mmol}), \mathrm{BHA}(0.70 \mathrm{~g}$, $3 \mathrm{mmol})$, potassium carbonate $(1.38 \mathrm{~g}, 10 \mathrm{mmol})$, a small amount of catalyst 18-crown-6, and solvent acetone $(20 \mathrm{~mL})$ were added to a $50 \mathrm{~mL}$ single-neck round-bottom flask equipped with a spherical condenser. The mixture was heated at reflux and magnetically stirred throughout, overnight. Potassium carbonate was removed by suction filtration, and acetone was removed by rotary evaporation to give a white powder displaying blue-green under an ultraviolet lamp. The white powder was chromatographically purified on silica gel eluting with dichloromethane: petroleum ether $(1: 1, V: V)$ as eluent to collect the third ribbon (showing a blue fluorescence). The eluent was evaporated to dryness and the residue was dried until constant weight in a vacuum oven to give AHP as a white solid $(0.374 \mathrm{~g}, 33 \%)$. Figure 1 was ${ }^{1} \mathrm{H}$ NMR spectrum of AHP in $\mathrm{CDCl}_{3} \cdot{ }^{1} \mathrm{H} \mathrm{NMR}\left(600 \mathrm{MHz}, \mathrm{CDCl}_{3}\right)$ $\delta(\mathrm{ppm}): 8.46(\mathrm{~d}, J=9.0 \mathrm{~Hz}, 1 \mathrm{H}), 8.11-8.08(\mathrm{~m}, 3 \mathrm{H}, \mathrm{H}-\mathrm{o}, \mathrm{H}-\mathrm{q}, \mathrm{H}-\mathrm{v}), 8.03(\mathrm{~d}, J=9.0 \mathrm{~Hz}, 1 \mathrm{H}), 7.97-7.94$ $(\mathrm{m}, 2 \mathrm{H}, \mathrm{H}-\mathrm{p}, \mathrm{H}-\mathrm{t}), 7.88(\mathrm{~d}, J=9.0 \mathrm{~Hz}, 1 \mathrm{H}), 7.53(\mathrm{~d}, J=8.4 \mathrm{~Hz}, 1 \mathrm{H}), 6.40(\mathrm{dd}, J=17.4 \mathrm{~Hz}, 1.2 \mathrm{~Hz}, 1 \mathrm{H})$, $6.12(\mathrm{dd}, J=17.4 \mathrm{~Hz}, 10.2 \mathrm{~Hz}, 1 \mathrm{H}), 5.80(\mathrm{dd}, J=10.2 \mathrm{~Hz}, 1.2 \mathrm{~Hz}, 1 \mathrm{H}), 4.33(\mathrm{t}, J=6.6 \mathrm{~Hz}, 2 \mathrm{H}), 4.21(\mathrm{t}$, $J=6.6 \mathrm{~Hz}, 2 \mathrm{H}), 2.05-2.01(\mathrm{~m}, 2 \mathrm{H}), 1.80-1.75(\mathrm{~m}, 2 \mathrm{H}), 1.72-1.67(\mathrm{~m}, 2 \mathrm{H}), 1.58-1.52(\mathrm{~m}, 2 \mathrm{H})$. Figure 2 was ${ }^{13} \mathrm{C}$ NMR spectrum of AHP in $\mathrm{CDCl}_{3}{ }^{13} \mathrm{C}$ NMR $\left(150 \mathrm{MHz}, \mathrm{CDCl}_{3}\right) \delta$ (ppm): 166.3, 153.2, 130.3, 128.6, 127.2, 125.4, 120.5, 109.2, 131.8, 131.7, 125.9, 125.3, 125.0 (5C, C-r, C-u, C-n, C-x, C-y), 126.3, 126.0, 124.9, 121.2 (4C, C-m, C-t, C-s, C-1), 124.2, 124.1 (2C, C-o, C-q), 68.9, 64.5, 29.4, 28.7, 26.0, 25.8. Figure 3 is the HR-APCI-FT-ICR-MS spectrum of AHP. HR-APCI-FT-ICR-MS revealed the parent ion peak at $m / z=373.1797$ (calcd for $\mathrm{C}_{25} \mathrm{H}_{25} \mathrm{O}_{3}$ : 373.1798, $[\mathrm{M}+\mathrm{H}]^{+}$).

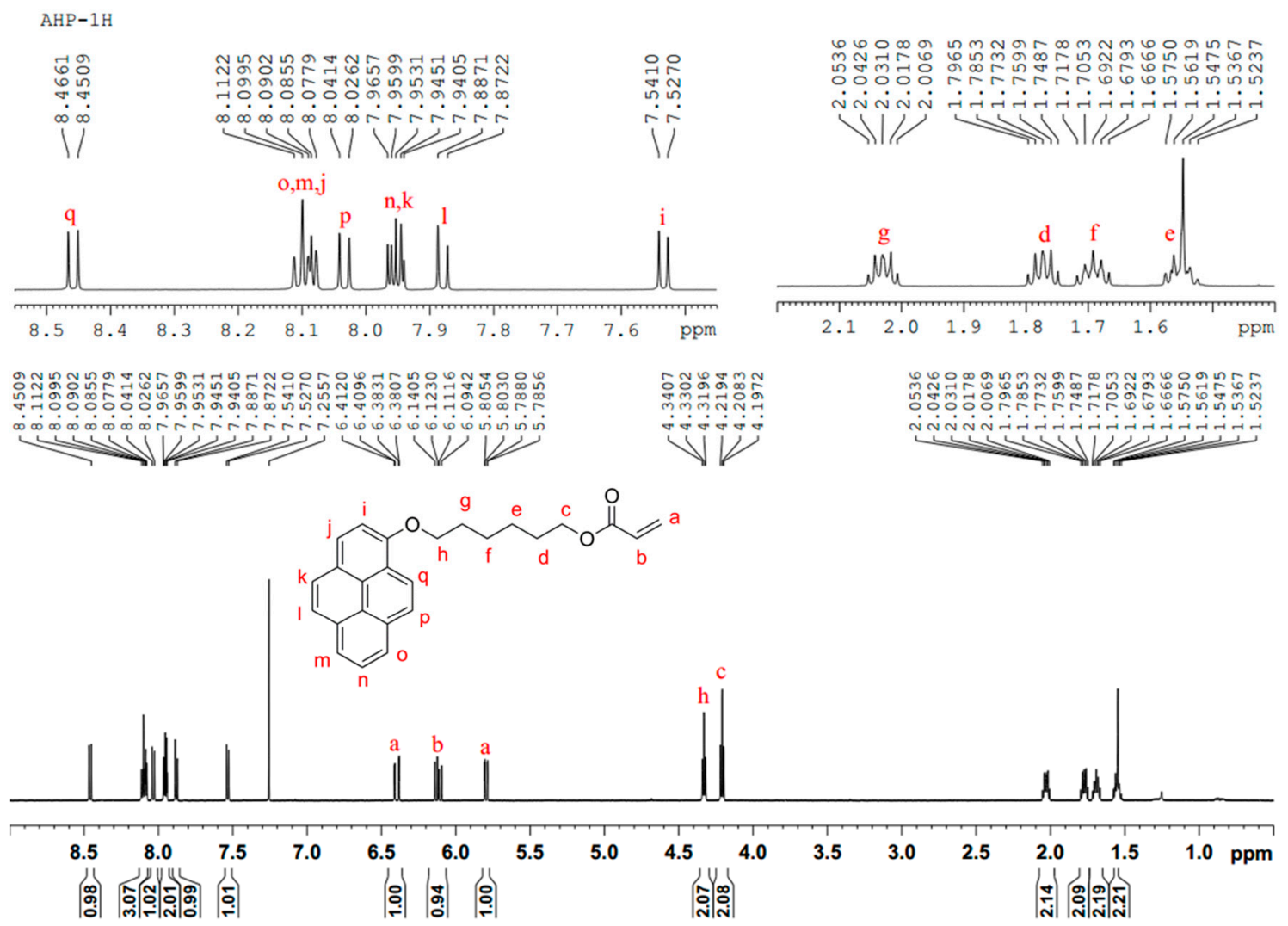

Figure 1. ${ }^{1} \mathrm{H}$ NMR spectrum of $\mathrm{AHP}$ in $\mathrm{CDCl}_{3}$. 


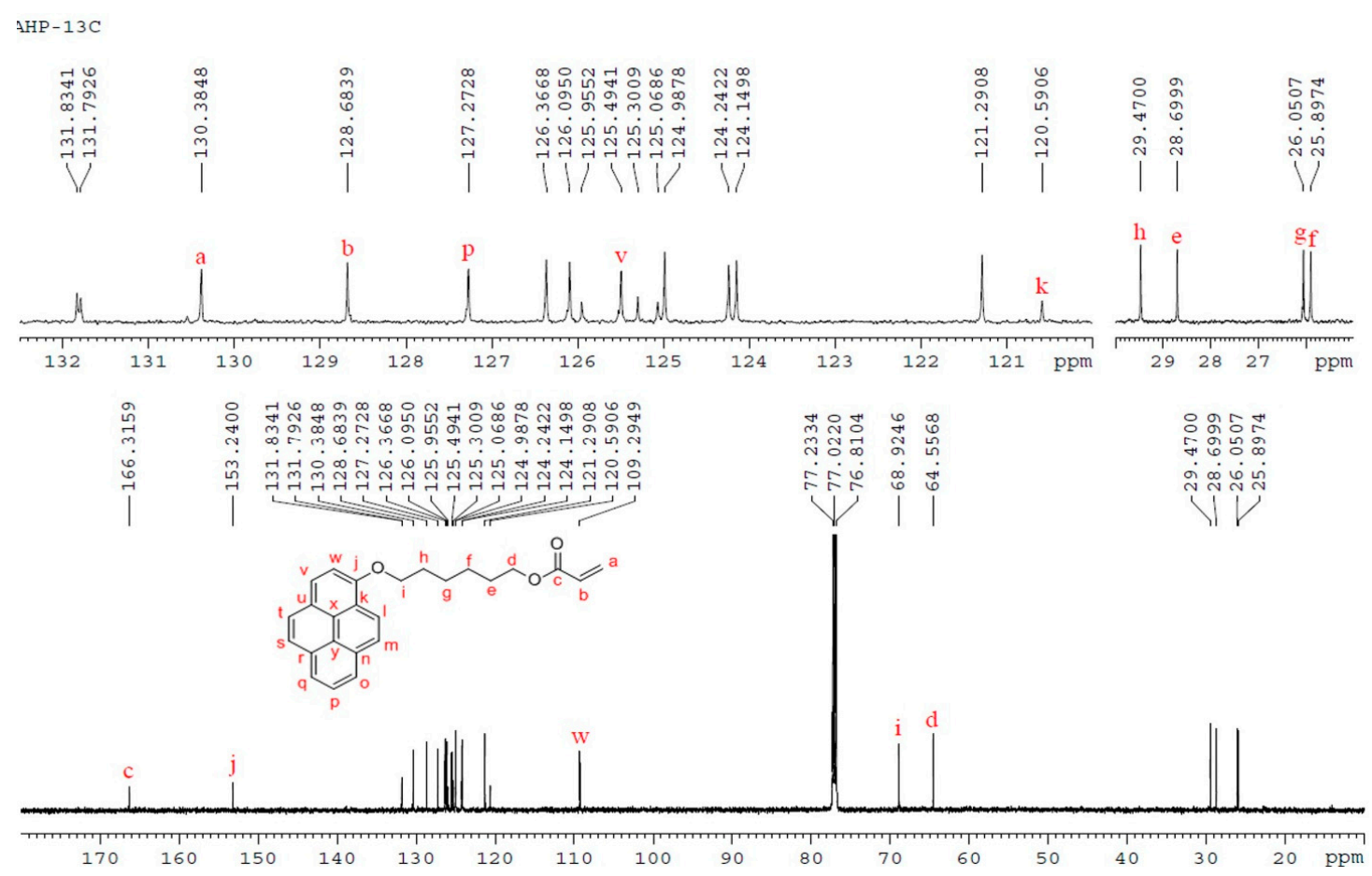

Figure 2. ${ }^{13} \mathrm{C}$ NMR spectrum of $\mathrm{AHP}$ in $\mathrm{CDCl}_{3}$.

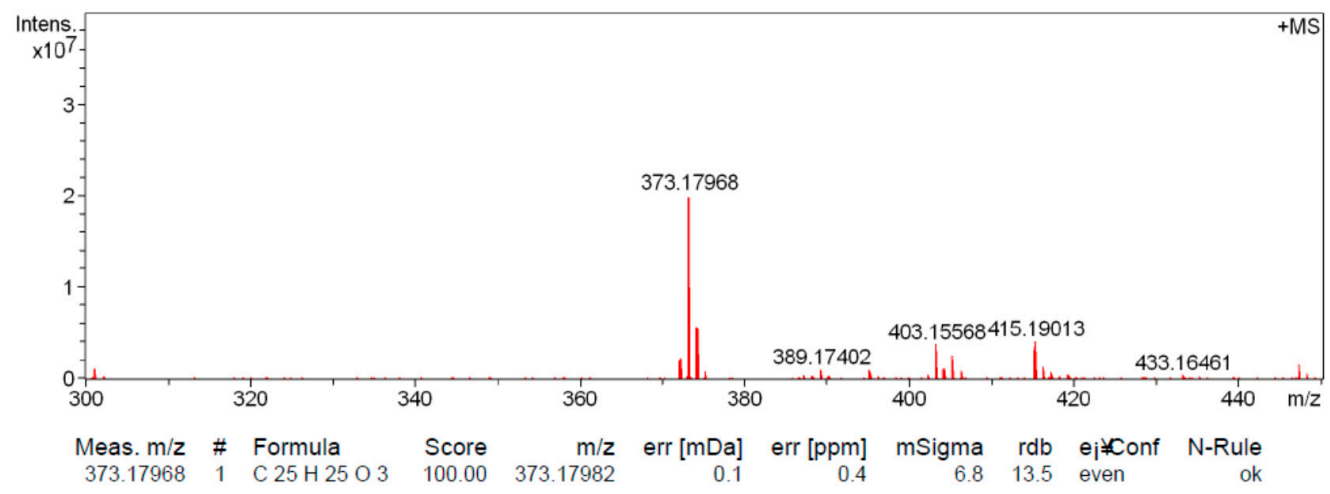

Figure 3. HR-APCI-FT-ICR-MS spectrum of AHP.

\subsection{Synthesis of 1-\{3'-S-[poly(N-Butoxycarbonyl-Acryloyl Ethylene Diamine)-2"-Methyl Propionic} acid]\}propionyloxy Hexyloxy Pyrene (P2) and 1-\{3'-S-[poly(Acryloyl Ethylene Diamine Hydrochloride)-2'-Methyl Propionic acid] spropionyloxy Hexyloxy Pyrene (P3)

The reaction mechanism of $\mathbf{P} 2$ and $\mathbf{P} 3$ was shown in Scheme 1. P1 (200.0 mg, $0.077 \mathrm{mmol})$, $\mathrm{NaBH}_{4}(3.8 \mathrm{mg}, 0.1 \mathrm{mmol})$, AHP $(34.0 \mathrm{mg}, 0.09 \mathrm{mmol})$, TEA $(10 \mu \mathrm{L}, 0.072 \mathrm{mmol})$, and solvent THF $(2 \mathrm{~mL})$ were added to a $5 \mathrm{~mL}$ eggplant-shaped flask. Then, the system was degassed for at least three cycles by pulling a vacuum and filling with nitrogen gas under magnetic stirring in an ice bath. The mixture was stirred at room temperature in a nitrogen atmosphere for $48 \mathrm{~h}$. After removal of the solvent, a pale yellow solid was obtained and chromatographically purified on silica gel eluting with dichloromethane to remove the first two ribbons which were the excess AHP and the reaction byproducts. Then methanol was used as eluent to give $\mathbf{P 2}$ as a wheat-colored solid $(0.202 \mathrm{~g}, 96 \%)$. P2 $(100 \mathrm{mg}$ ) was dissolved in $10 \mathrm{~mL}$ of $\mathrm{THF}$, and then $\mathrm{HCl}$ gas was passed through the solution for the purpose of deprotection of the resulting Boc-protected polymer (P2) until an amount of precipitate formed. The formed precipitate was filtered and washed with THF, and dried in a vacuum oven to afford the desired water-soluble fluorescent polymer $\mathbf{P} 3$ as a pale brown solid $(71.5 \mathrm{mg}, 95 \%)$. 


\section{Results and Discussion}

\subsection{The reaction Mechanism of the One-Pot Reaction}

Scheme 1 outlines the basic reaction mechanism. Thiol is obtained by a reduction reaction of the trithioester of P1. The weak sulfur-hydrogen bond of thiols are readily oxidized to disulfide bonds during storage or purification, resulting in difficulty of subsequent click-chemistry reactions. The one-pot method used in this paper can solve the problem easily. In the same system, both the reduction reaction of the trithioester bond of $\mathbf{P 1}$ to thiol, the click reaction of thiol, and the carbon-carbon double bond of AHP occurred simultaneously. As a result, a Boc-protected amino group fluorescent polymer (P2) was synthesized, then water-soluble pyrene-containing fluorescent polymer (P3) with a defined structure was obtained by the deprotection of the resulting Boc-protected polymer (P2) with aqueous $\mathrm{HCl}$.

\subsection{FTIR Analysis of AHP, $\mathbf{P} 2$, and $\mathbf{P 3}$}

Figure 4 was the FTIR spectra of AHP, P2, and P3. As seen from the AHP spectrum, the characteristic stretching vibration absorption peak of the ester carbonyl group $\mathrm{C}=\mathrm{O}$ bond was shown at $1713 \mathrm{~cm}^{-1}$. The absorption peak was shown at $1596 \mathrm{~cm}^{-1}$ resulting from that stretching vibration of the $\mathrm{C}=\mathrm{C}$ bond in acrylic ester $(-\mathrm{OCO}-\mathrm{C}=\mathrm{C})$. Absorption peaks at approximately 2939 and $2862 \mathrm{~cm}^{-1}$ were assigned to the asymmetric and symmetric stretching vibration and asymmetric stretching vibration of methylene group $\mathrm{C}-\mathrm{H}$ bond, respectively. The peak at $1408 \mathrm{~cm}^{-1}$ responded to the $\mathrm{C}-\mathrm{H}$ bond shear vibration of the vinyl end group $\left(=\mathrm{CH}_{2}\right)$. At around $1192 \mathrm{~cm}^{-1}$ the absorption peak was the asymmetric stretching vibration of the $\mathrm{C}-\mathrm{O}-\mathrm{C}$ bond. Two absorption peaks were shown at 1620 and $1510 \mathrm{~cm}^{-1}$ resulting from that stretching vibration of the aromatic ring skeleton of pyrene. There were no blockbuster absorption peaks of acid at $3300-2500 \mathrm{~cm}^{-1}$ in this spectrum. Comparing the spectra of $\mathbf{P} 2$ and $\mathbf{P} 3$, the biggest difference was the absorption peak from 4000 to $2500 \mathrm{~cm}^{-1}$. The absorption peaks shown at $3500-3300 \mathrm{~cm}^{-1}$ and $3330-3150 \mathrm{~cm}^{-1}$ were the stretching vibrations of the $\mathrm{N}-\mathrm{H}$ bond in the primary amine and primary amine salt in the $\mathbf{P} 3$ spectrum, respectively, which was due to the removal of the Boc group and formed a $-\mathrm{NH}_{2}$ and $-\mathrm{NH}_{2} \cdot \mathrm{HCl}$ structure with $\mathrm{HCl}$ gas in repeating units. At around 1366 and $1390 \mathrm{~cm}^{-1}$ absorption peaks were the vibration of the $\mathrm{C}-\mathrm{H}$ bond of $t$-butyl in the $\mathbf{P 2}$ spectrum, and the former intensity was about twice as strong as the latter. The two peaks significantly reduced after removal of the Boc protection in the $\mathbf{P} 3$ spectrum, at around $1693 \mathrm{~cm}^{-1}$ the ester carbonyl group $\mathrm{C}=\mathrm{O}$ bond stretching vibration peak disappeared, remaining only at $1653 \mathrm{~cm}^{-1}$, the solid amide $\mathrm{C}=\mathrm{O}$ bond stretching absorption peak, which indicated that the number and morphology of the $\mathrm{C}=\mathrm{O}$ bond was changed. These results clearly manifested the formation of AHP, P2, and P3.

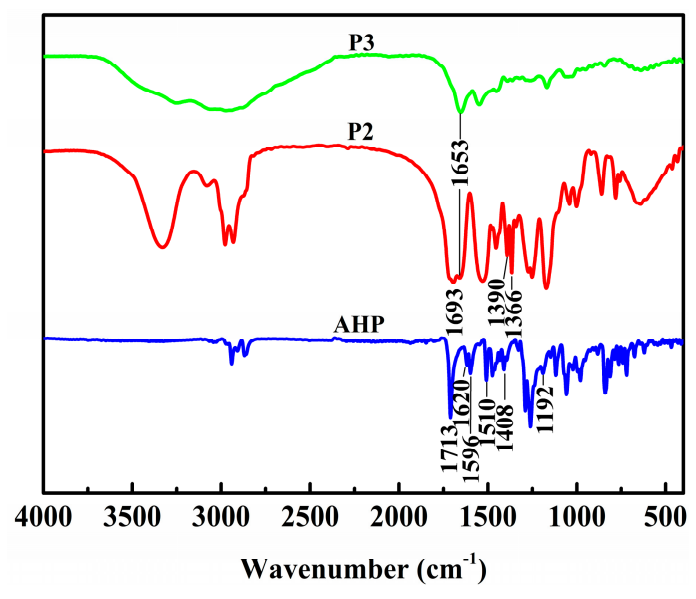

Figure 4. FTIR spectra of AHP, P2, and P3. 


\subsection{NMR Analysis of $\mathbf{P 3}$}

P3 is soluble in water. It is characterized by NMR, UV-VIS, and PL spectroscopy. Figure 5 showed the ${ }^{1} \mathrm{H}$ NMR spectrum of P3. ${ }^{1} \mathrm{H}$ NMR $\left(600 \mathrm{MHz}, \mathrm{D}_{2} \mathrm{O}, \delta\right)$ showed a chemical shift peak from 7.60 to $8.40 \mathrm{ppm}$; these signals were assigned to the aromatic protons in pyrene units. There were two chemical shift peaks from 1.32 to $1.82 \mathrm{ppm}$ and 1.94 to $2.37 \mathrm{ppm}$, which was attributed to protons of $\mathrm{CH}_{2}$ and $\mathrm{CH}$ groups in the polymer main chain. Two chemical shift peaks from 2.97 to $3.20 \mathrm{ppm}$ and 3.21 to $3.60 \mathrm{ppm}$ corresponding to protons of $\mathrm{CH}_{2}-\mathrm{NHCO}$ and $\mathrm{CH}_{2}-\mathrm{NH}_{2} \cdot \mathrm{HCl}$ in the polymer side chain were observed. There were two chemical shift peaks from 3.95 to $4.12 \mathrm{ppm}$ and 3.75 to $3.80 \mathrm{ppm}$, which were assigned to protons of $\mathrm{COO}-\mathrm{CH}_{2}$ and $\mathrm{C}_{6} \mathrm{H}_{4} \mathrm{O}-\mathrm{CH}_{2}$. The ${ }^{1} \mathrm{H}$ NMR spectrum also confirmed the presence of the pyrene unit in the $\mathbf{P} 3$ structure. This proved that the pyrene unit was really attached to the $\mathbf{P 1}$ chain and $\mathbf{P} 2$ was synthesized after the click reaction of thiol reduced from P1 and the carbon-carbon double bond of AHP.

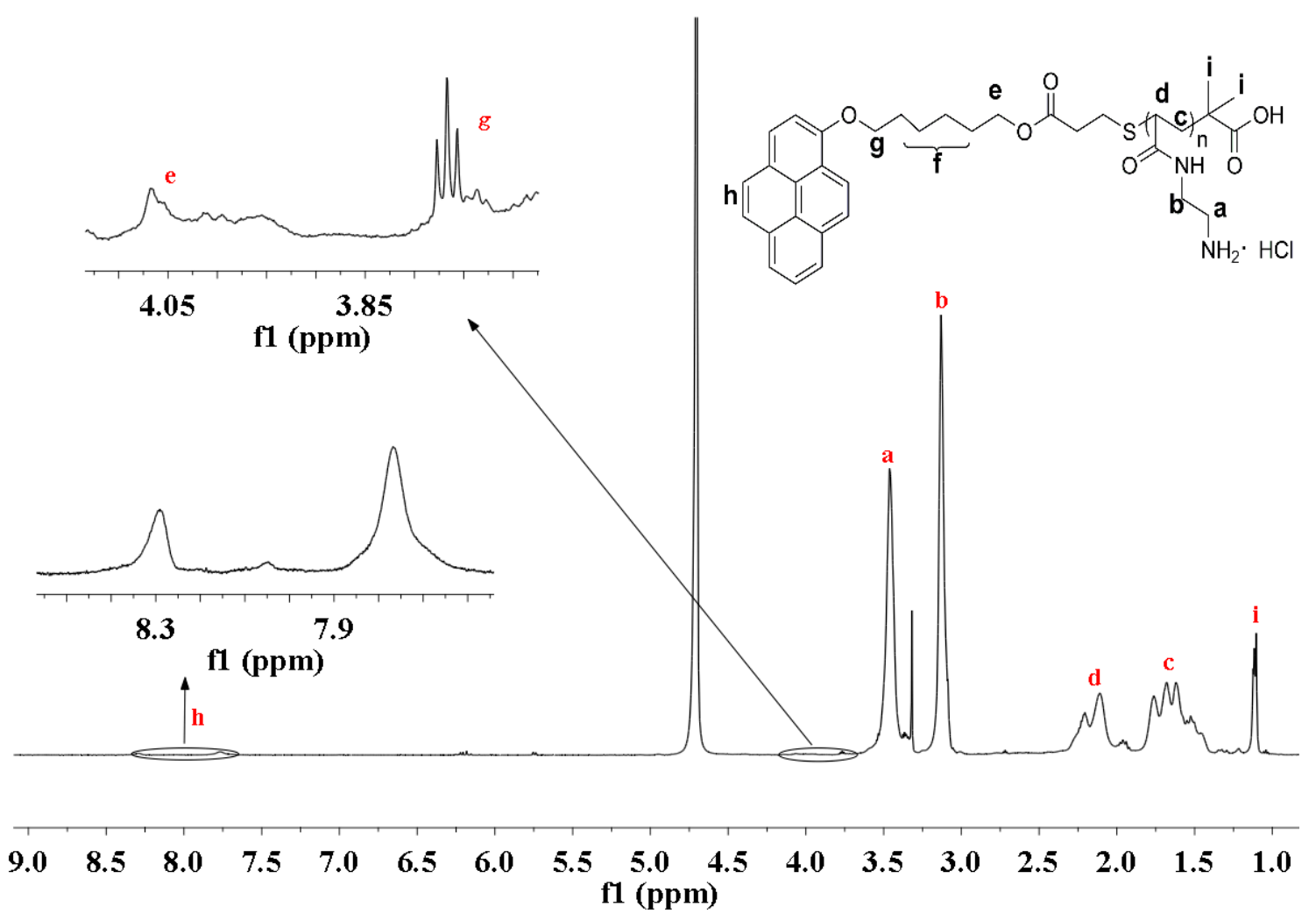

Figure 5. ${ }^{1} \mathrm{H}$ NMR spectrum of $\mathbf{P} 3$ in $\mathrm{D}_{2} \mathrm{O}$.

\subsection{GPC Analysis}

Figure 6 are the GPC chromatograms for the standard sample (polystyrene), P1, and P2 which were shown as a blue line, red line, and green line, respectively. The $M_{n}$ of the standard sample was labeled as $3.79 \times 10^{3} \mathrm{~g} \cdot \mathrm{mol}^{-1}$. The $M_{\mathrm{n}}$ of $\mathbf{P} \mathbf{1}$ and $\mathbf{P} 2$ were given by the software as $2.60 \times 10^{3} \mathrm{~g} \cdot \mathrm{mol}^{-1}$ and $2.50 \times 10^{3} \mathrm{~g} \cdot \mathrm{mol}^{-1}$, respectively. PDI of $\mathbf{P} 1$ is 1.39 . The theoretical molecular weight of $\mathbf{P 2}$ is $M_{\mathrm{n}}(\mathbf{P} 2)=M(\mathrm{AHP})+M_{\mathrm{n}}(\mathbf{P 1})-M\left(\mathrm{CS}_{2} \mathrm{C}_{12} \mathrm{H}_{25}\right)=372+2600-245=2727 \mathrm{~g} \cdot \mathrm{mol}^{-1}$. The analytical datum from the GPC experiment was similar with the theoretical result, which proved that AHP bonded with the P1 chain as shown in Scheme 1. 


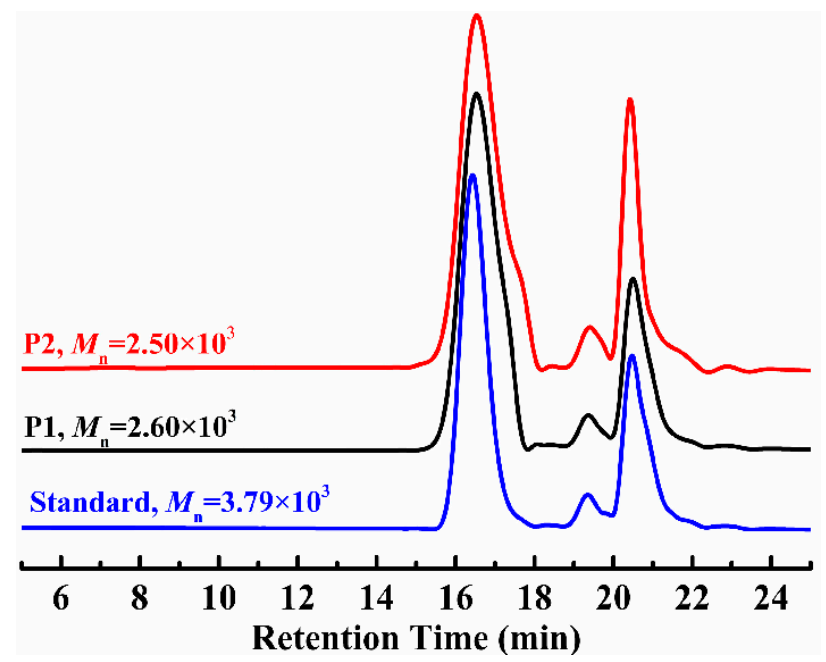

Figure 6. GPC chromatograms for P1, P2, and the standard $\left(M_{\mathrm{n}}=3.79 \times 10^{3} \mathrm{~g} \cdot \mathrm{mol}^{-1}\right)$.

\subsection{UV-VIS and PL Analysis}

Figure 7 is the UV-VIS spectra of AHP, $\mathbf{P 1}$, and $\mathbf{P 2}$ in $\mathrm{CH}_{2} \mathrm{Cl}_{2}$. As it can be seen from the $\mathbf{P 1}$ spectrum, there was only one characteristic absorption peak at $310 \mathrm{~nm}$ resulting from $\mathrm{C}=\mathrm{S}$ double bond [35,37]; in sharp contrast, it had disappeared in the UV-VIS spectrum of P2. The numbers and positions of the UV-VIS absorption peak of $\mathbf{P} 2$ were consistent with those of AHP.

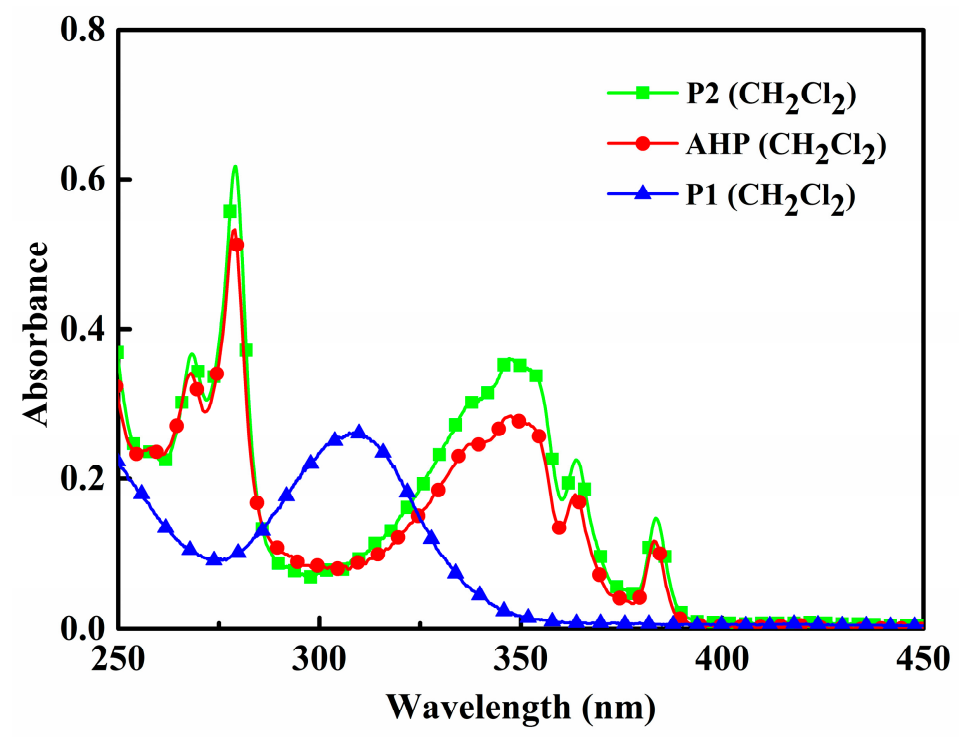

Figure 7. UV-VIS spectra of AHP, $\mathbf{P 1}$, and $\mathbf{P} 2$ in $\mathrm{CH}_{2} \mathrm{Cl}_{2}$.

Figure 8 is the PL spectra of AHP, $\mathbf{P 1}$, and $\mathbf{P 2}$ in $\mathrm{CH}_{2} \mathrm{Cl}_{2}$. The fluorescence emission peak of P1 using its maximum absorption wavelength of $310 \mathrm{~nm}$ in the UV-VIS spectrum as the excitation wavelength was not observed. $345 \mathrm{~nm}$ was chosen as the excitation wavelength of AHP and P2 according to the reference literature $[34,38]$. AHP and $\mathbf{P 2}$ showed the fluorescence spectra of the same shape and three typical fluorescence emission peaks at 387, 407, and $429 \mathrm{~nm}$, respectively. Since unreacted AHP had been removed during the processing of $\mathbf{P} 2$ purified by silica gel column chromatography, these data indicated that $\mathbf{P 2}$ fluorescence emission was not due to residual AHP, but from pyrene units in P2. Figures 7 and 8 revealed that the pyrene-containing unit AHP was really introduced to the $\mathbf{P 1}$ chain and $\mathbf{P} \mathbf{2}$ was successfully prepared after one-pot reaction. 


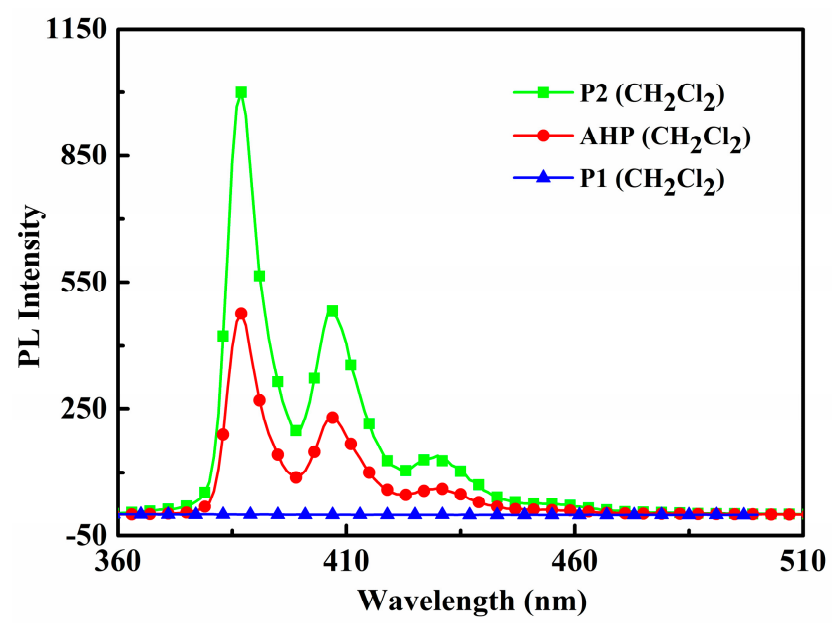

Figure 8. PL spectra of AHP, P1, and $\mathbf{P 2}$ in $\mathrm{CH}_{2} \mathrm{Cl}_{2}$.

P2 was soluble in common organic solvents, such as dichloromethane, trichloromethane, and THF, and exhibited a bright blue-violet fluorescence emission band in solution. P3 was soluble in water and exhibited a bright blue-violet fluorescence emission band in water, too. Figures 9 and 10 were UV-VIS and PL spectra of AHP in $\mathrm{H}_{2} \mathrm{O}, \mathbf{P} 2$ in dichloromethane, and $\mathbf{P} 3$ in $\mathrm{H}_{2} \mathrm{O}$, respectively. Since AHP was insoluble in water, there were no UV-VIS absorption peaks and fluorescence emission peaks of AHP in the aqueous solution. P3 had good water solubility, and showed the UV-VIS characteristic absorption bands of pyrene, and were consistent with those of $\mathbf{P} \mathbf{2}$ in dichloromethane solution. There were three fluorescence emission peaks at 387, 407, and $429 \mathrm{~nm}$ of P3 in aqueous solution, respectively, which were consistent with those of P2 in dichloromethane solution. Therefore, UV-VIS and PL measurement results showed that: P2 was prepared by the one-pot method of thiol reduced from P1 and the carbon-carbon double bond of AHP; water-soluble fluorescent polymer P3 was obtained by the deprotection of the resulting Boc-protected polymer (P2); and it was also confirmed that UV-VIS absorption and fluorescence emission of $\mathbf{P 2}$ and $\mathbf{P 3}$ come from their own structure, rather than the residual AHP. The fluorescence quantum yields of $\mathbf{P} 2\left(\Phi_{\mathrm{u}}=0.44\right)$ in dilute THF and $\mathbf{P} 3\left(\Phi_{\mathrm{u}}=0.39\right)$ in dilute aqueous solution were measured using DPA as a reference substance $\left(\Phi_{\mathrm{S}}=0.90\right)$ [39] according to the formula:

$$
\Phi_{\mathrm{u}}=\Phi_{\mathrm{s}}\left(n_{\mathrm{u}}^{2} F_{\mathrm{u}} / n_{\mathrm{s}}^{2} F_{\mathrm{s}}\right)\left(A_{\mathrm{s}} / A_{\mathrm{u}}\right)
$$

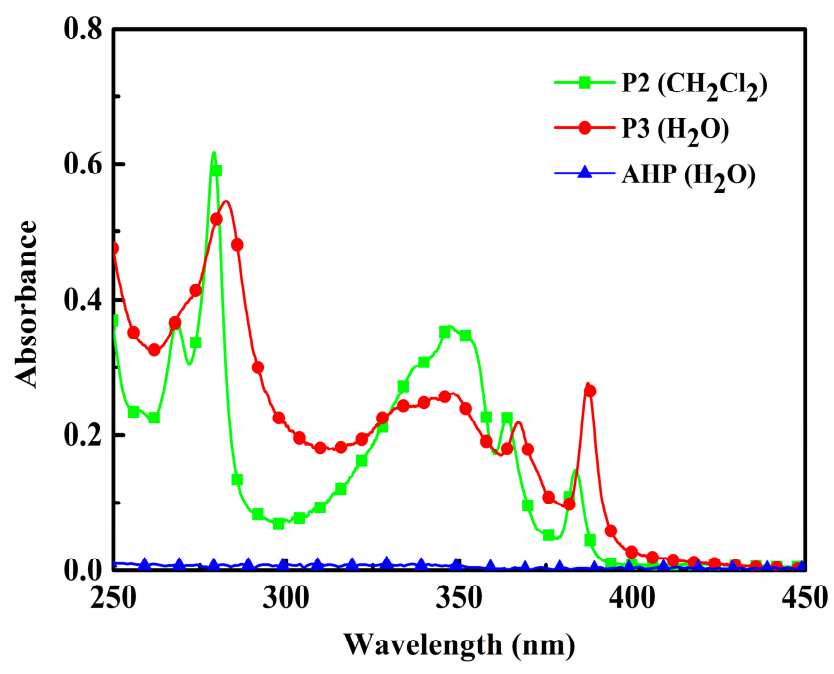

Figure 9. UV-VIS spectra of AHP, P2, and P3. 


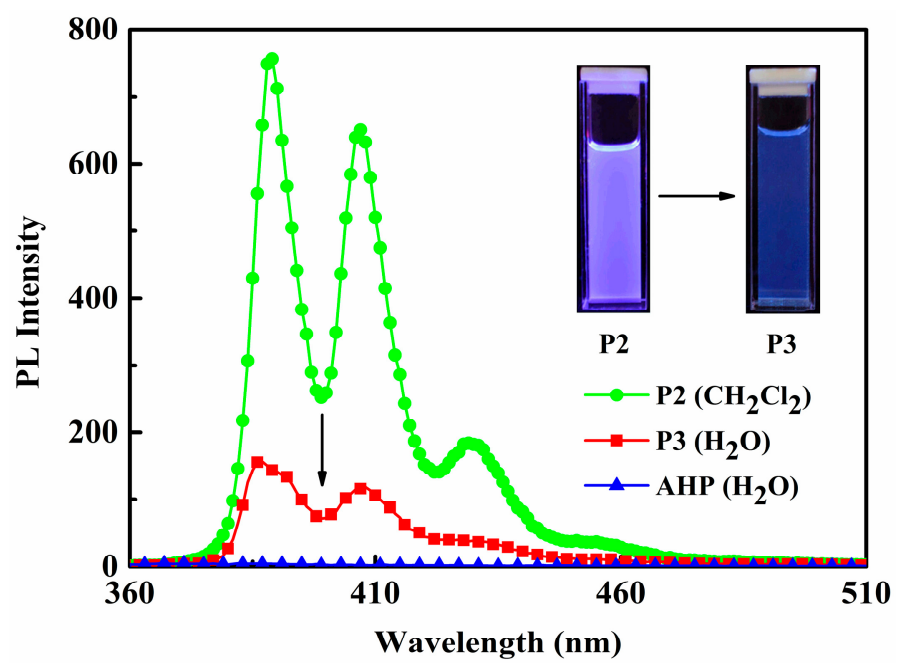

Figure 10. PL spectra of $\mathbf{P} 2$ in $\mathrm{CH}_{2} \mathrm{Cl}_{2}, \mathrm{AHP}$, and $\mathbf{P} 3$ in $\mathrm{H}_{2} \mathrm{O}$.

\section{Conclusions}

Reversible addition-fragmentation chain transfer polymerization was used to obtain a Boc-protected amino group polymer (P1) with trithioester as a terminal group. The trithioester bond of P1 was reduced to thiol using sodium borohydride as the reductant. The click reaction of thiol and the carbon-carbon double bond of AHP was used to prepare a Boc-protected amino group and the defined structure of a fluorescent polymer containing a pyrene unit (P2). A water-soluble pyrene-containing fluorescent polymer (P3) was synthesized by the deprotection of the resulting Boc-protected polymer (P2) with aqueous $\mathrm{HCl}$. P3 was soluble in water and exhibited a bright blue-violet fluorescence emission band in aqueous solution, which had the similar photoluminescent spectra to those of AHP and $\mathbf{P} \mathbf{2}$ in dichloromethane. The fluorescent quantum yields of $\mathbf{P 2}$ in dilute tetrahydrofuran and P3 in dilute aqueous solution could reach 0.44 and 0.39 , respectively.

Supplementary Materials: Supplementary materials can be accessed at: http:// www.mdpi.com/2073-4360/7/ 12/1538/s1.

Acknowledgments: The authors thank the financial supports from National Natural Science Foundation of China (Nos. 21274037, 21304029 and 21474026), Natural Science Foundation of Hebei Province, China (Nos. B2013201174 and B2014201005). The authors thank Kerang Wang (College of Chemistry and Environmental Science, Hebei University) for his help in UV-VIS and PL experiments. The authors also thank Shenghui Li, Hua Chen, Jinchong Xiao, Hongyan Li and Xiaoke Wang (College of Chemistry and Environmental Science, Hebei University), for their help in NMR spectroscopy test and analysis.

Author Contributions: Hongchi Zhao and Yonggang Wu designed the experiments; Xiaomeng Li, Miaomiao Wang, Haijian Tan, Qingmin Yang, Aiqing Wang, Libin Bai performed the experiments; Xiaomeng Li and Miaomiao Wang wrote the paper.

Conflicts of Interest: The authors declare no conflict of interest.

\section{References}

1. Miranda, O.R.; Creran, B.; Rotello, V.M. Array-based sensing with nanoparticles: "Chemical noses" for sensing biomolecules and cell surfaces. Curr. Opin. Chem. Biol. 2010, 14, 728-736. [CrossRef] [PubMed]

2. Dutta, R.; Scott, M.D.; Haldar, M.K.; Ganguly, B.; Srivastava, D.K.; Friesner, D.L.; Mallik, S. Fluorescent water soluble polymers for isozyme-selective interactions with matrix metalloproteinase-9. Bioorg. Med. Chem. Lett. 2011, 21, 2007-2010. [CrossRef] [PubMed]

3. Bajaj, A.; Miranda, O.R.; Phillips, R.; Kim, I.B.; Jerry, D.J.; Bunz, U.H.; Rotello, V.M. Array-based sensing of normal, cancerous, and metastatic cells using conjugated fluorescent polymers. J. Am. Chem. Soc. 2010, 132, 1018-1022. [CrossRef] [PubMed] 
4. Scott, M.D.; Dutta, R.; Haldar, M.K.; Guo, B.; Friesner, D.L.; Mallik, S. Differentiation of prostate cancer cells using flexible fluorescent polymers. Anal. Chem. 2012, 84, 17-20. [CrossRef] [PubMed]

5. You, J.; Park, T.; Kim, J.; Heo, J.S.; Kim, H.S.; Kim, H.O.; Kim, E. Highly fluorescent conjugated polyelectrolyte for protein sensing and cell-compatible chemosensing applications. ACS Appl. Mater. Interfaces 2014, 5, 3305-3311. [CrossRef] [PubMed]

6. Traina, C.A.; Bakus II, R.C.; Bazan, G.C. Design and synthesis of monofunctionalized, water-soluble conjugated polymers for biosensing and imaging applications. J. Am. Chem. Soc. 2011, 133, 12600-12607. [CrossRef] [PubMed]

7. Schillén, K.; Anghel, D.F.; Miguel, M.G.; Lindman, B. Association of naphthalene-labeled poly(acrylic acid) and interaction with cationic surfactants fluorescence studies. Langmuir 2000, 16, 10528-10539. [CrossRef]

8. Costa, T.; Miguel, M.G.; Lindman, B.; Schillén, K.; Lima, J.C.; Seixas de Melo, J. Self-assembly of a hydrophobically modified naphthalene-labeled poly(acrylic acid) polyelectrolyte in water: Organic solvent mixtures followed by steady-state and time-resolved fluorescence. J. Phys. Chem. B 2005, 109, 3243-3251. [CrossRef] [PubMed]

9. Oyama, H.T.; Tang, W.T.; Frank, C.W. Complex formation between poly(acry1ic acid) and pyrene-labeled poly(ethylene glycol) in aqueous solution. Macromolecules 1987, 20, 474-480. [CrossRef]

10. Hemker, D.J.; Garza, V.; Frank, C.W. Complexation of poly(acry1ic acid) and poly(methacry1ic acid) with pyrene-end-labeled poly(ethylene glycol). $\mathrm{pH}$ and fluorescence measurements. Macromolecules 1990, 23, 4411-4418. [CrossRef]

11. Zhang, W.J.; Peng, B.; Tian, F.; Qin, W.J.; Qian, X.H. Facile preparation of well-defined hydrophilic core-shell upconversion nanoparticles for selective cell membrane glycan labeling and cancer cell imaging. Anal. Chem. 2014, 86, 482-489. [CrossRef] [PubMed]

12. Choi, Y.; Kim, K.; Hong, S.; Kim, H.; Kwon, Y.J.; Song, R. Intracellular protein target detection by quantum dots optimized for live cell imaging. Bioconjug. Chem. 2011, 22, 1576-1586. [CrossRef] [PubMed]

13. Roth, P.J.; Boyer, C.; Lowe, A.B.; Davis, T.P. RAFT polymerization and thiol chemistry: Acomplementary pairing for implementing modern macromolecular design. Macromol. Rapid Commun. 2011, 32, 1123-1143. [CrossRef] [PubMed]

14. Harvison, M.A.; Davis, T.P.; Lowe, A.B. Macromolecular thiolysis of oxiranes: End-group modification of RAFT prepared homopolymers. Polym. Chem. 2011, 2, 1347-1354. [CrossRef]

15. Kolb, H.C.; Finn, M.G.; Barry Sharpless, K. Click chemistry: Diverse chemical function from a few good reactions. Angew. Chem. Int. Ed. 2001, 40, 2004-2021. [CrossRef]

16. Kappe, C.O.; Van der Eycken, E. Click chemistry under non-classical reaction conditions. Chem. Soc. Rev. 2010, 39, 1280-1290. [CrossRef] [PubMed]

17. Clavé, G.; Campidelli, S. Efficient covalent functionalisation of carbon nanotubes: The use of "click chemistry". Chem. Sci. 2011, 2, 1887-1896. [CrossRef]

18. Negishi, K.; Mashiko, Y.; Yamashita, E.; Otsuka, A.; Hasegawa, T. Synthesis of well-defined, water-soluble hyperbranched polyamides by chain-growth condensation polymerization of $\mathrm{AB}_{2}$ monomer. Polymers 2012, 4, 1170-1182.

19. Moses, J.E.; Moorhouse, A.D. The growing applications of click chemistry. Chem. Soc. Rev. 2007, 8, 1249-1262. [CrossRef] [PubMed]

20. Hoyle, C.E.; Bowman, C.N. Thiol-ene click chemistry. Angew. Chem. Int. Ed. 2010, 49, 1540-1573. [CrossRef] [PubMed]

21. Korthals, B.; Morant-Miñana, M.C.; Schmid, M.; Mecking, S. Functionalization of polymer nanoparticles by thiol-ene addition. Macromolecules 2010, 43, 8071-8078. [CrossRef]

22. Prasath, R.A.; Gokmen, M.T.; Espeel, P.; du Prez, F.E. Thiol-ene and thiol-yne chemistry in microfluidics: A straight forward method towards macroporous and nonporous functional polymer beads. Polym. Chem. 2010, 1, 685-692. [CrossRef]

23. Iskin, B.; Yilmaz, G.; Yagci, Y. ABC type miktoarm star copolymers through combination of controlled polymerization techniques with thiol-ene and azide-alkyne click reactions. J. Polym. Sci. Polym. Chem. 2011, 49, 2417-2422. [CrossRef]

24. Montañnez, M.I.; Campos, L.M.; Antoni, P.; Hed, Y.; Walter, M.V.; Krull, B.T.; Khan, A.; Hult, A.; Hawker, C.; Malkoch, M. Accelerated growth of dendrimers via thiol-ene and esterification reactions. Macromolecules 2010, 43, 6004-6013. [CrossRef] 
25. Balasubramanian, R.; Kalaitzis, Z.M.; Cao, W. Solvent dependent morphologies in thiol-ene photopolymerization: A facile route to the synthesis of resorcinarene nanocapsules. J. Mater. Chem. 2010, 20, 6539-6543. [CrossRef]

26. Campos, L.M.; Killops, K.L.; Sakai, R.; Paulusse, J.M.J.; Damiron, D.; Drockenmuller, E.; Messmore, B.W.; Hawker, C.J. Development of thermal and photochemical strategies for thiol-ene click polymer functionalization. Macromolecules 2008, 41, 7063-7070. [CrossRef]

27. Zimerman, O.E.; Cosa, J.J.; Previtallj, C.M. Binding of ionic pyrene derivatives to polyelectrolytes. A UV absorption and fluorescence study. J. Macromol. Sci. A 1994, 31, 859-872. [CrossRef]

28. Nakagawa, K.; Numata, Y.; Ishino, H.; Tanaka, D.; Kobayashi, T.; Tokunaga, E. Excimer luminescence from nonresonantly excited pyrene and perylene molecules in solution. J. Phys. Chem. A 2013, 117, 11449-11455. [CrossRef] [PubMed]

29. Carbonell, E.; Delgado-Pinar, E.; Pitarch-Jarque, J.; Alarcón, J.; García-España, E. Boehmite supported pyrene polyamine systems as probes for iodide recognition. J. Phys. Chem. C 2013, 117, 14325-14331. [CrossRef]

30. Duhamel, J. Internal dynamics of dendritic molecules probed by pyrene excimer formation. Polymers 2012, 4, 211-239. [CrossRef]

31. Mahapatra, A.K.; Mondal, S.; Maiti, K.; Manna, S.K.; Maji, R.; Mandal, D.; Mandal, S.; Goswami, S.; Quah, C.K.; Funde, H.K. A pyrene thiazole conjugate as a ratiometric chemosensor with high selectivity and sensitivity for tin $\left(\mathrm{Sn}^{4+}\right)$ and its application in imaging livecells. RSC Adv. 2014, 4, 56605-56614. [CrossRef]

32. Zou, L.; Wang, X.; Shi, Y.K.; Wang, J.Y.; Pei, J. Fusion at the non-K-region of pyrene: An alternative strategy to extend the $\pi$-conjugated plane of pyrene. Org. Lett. 2013, 15, 4378-4381. [CrossRef] [PubMed]

33. Das, S.; Sahana, A.; Lohar, S.; Sarkar, B.; Mukhopadhya, S.K.; Banerjee, A.; Das, D. A visible light excitable pyrene-naphthalene conjugate for ON fluorescence sensing of histidine in living cells. RSC Adv. 2014, 4, 7495-7499. [CrossRef]

34. Edkins, R.M.; Fucke, K.; Peach, M.J.G.; Crawford, A.G.; Marder, T.B.; Beeby, A. Syntheses, structures, and comparison of the photophysical properties of cyclometalated iridium complexes containing the isomeric 1-and 2-(2'-pyridyl)pyrene ligands. Inorg. Chem. 2013, 52, 9842-9860. [CrossRef] [PubMed]

35. Liu, N.; Wu, Y.G.; Bai, L.B.; Wang, Y.; Huang, H.C.; Zhao, H.C.; Ba, X.W. Preparation of pH-sensitive fluorescent poly(acryl-2-aminoethy-lammonium hydrochloride) with porphyrin or fluorene by one-pot method. Chem. J. Chin. Univ. 2014, 35, 1111-1118.

36. Lai, J.T.; Filla, D.; Shea, R. Functional polymers from novel carboxyl-terminated trithiocarbonates as highly efficient RAFT agents. Macromolecules 2002, 35, 6754-6756. [CrossRef]

37. Wang, Y.; Tan, H.J.; Li, X.M.; Qian, Y.X.; Bai, L.B.; Wu, Y.G.; Lv, S.F.; Zhao, H.C. Preparation of the water-soluble fluorene-containing fluorescent polymer by one-pot method. Macromol. Res. 2015, 23, 891-897. [CrossRef]

38. Hayashida, O.; Kaku, Y. Synthesis of dabsyl-appended cyclophanes and their heterodimer formation with pyrene-appended cyclophanes. J. Org. Chem. 2013, 78, 10437-10442. [CrossRef] [PubMed]

39. Zhu, B.; Han, Y.; Sun, M.H.; Bo, Z.S. Water-soluble dendronized polyfluorenes with an extremely high quantum yield in water. Macromolecules 2007, 13, 4494-4500. [CrossRef]

(C) 2015 by the authors; licensee MDPI, Basel, Switzerland. This article is an open access article distributed under the terms and conditions of the Creative Commons by Attribution (CC-BY) license (http:/ / creativecommons.org/licenses/by/4.0/). 